May 1999 • NREL/CP-520-26355

\title{
Anisotropy in Hydrogenated Amorphous Silicon Films as Observed Using Polarized FTIR-ATR Spectroscopy
}

J.D. Webb, L.M. Gedvilas, R.S. Crandall, E. Iwaniczko, B.P. Nelson, A.H. Mahan, R. Reedy, and R.J. Matson

Presented at the Materials Research Society's 1999 Spring Meeting

San Francisco, California April 5-9, 1999

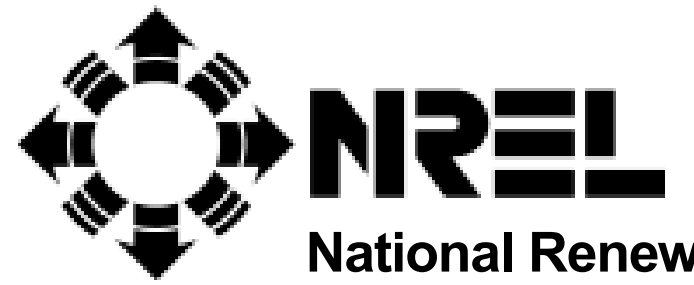

1617 Cole Boulevard Golden, Colorado 80401-3393

NREL is a U.S. Department of Energy Laboratory Operated by Midwest Research Institute $\bullet$ Battelle $\bullet$ Bechtel Contract No. DE-AC36-98-G010337 


\section{NOTICE}

This report was prepared as an account of work sponsored by an agency of the United States government. Neither the United States government nor any agency thereof, nor any of their employees, makes any warranty, express or implied, or assumes any legal liability or responsibility for the accuracy, completeness, or usefulness of any information, apparatus, product, or process disclosed, or represents that its use would not infringe privately owned rights. Reference herein to any specific commercial product, process, or service by trade name, trademark, manufacturer, or otherwise does not necessarily constitute or imply its endorsement, recommendation, or favoring by the United States government or any agency thereof. The views and opinions of authors expressed herein do not necessarily state or reflect those of the United States government or any agency thereof.

Available to DOE and DOE contractors from:

Office of Scientific and Technical Information (OSTI)

P.O. Box 62

Oak Ridge, TN 37831

Prices available by calling 423-576-8401

Available to the public from:

National Technical Information Service (NTIS)

U.S. Department of Commerce

5285 Port Royal Road

Springfield, VA 22161

$703-605-6000$ or $800-553-6847$

or

DOE Information Bridge

http://www.doe.gov/bridge/home.html

Printed on paper containing at least $50 \%$ wastepaper, including $20 \%$ postconsumer waste 


\title{
ANISOTROPY IN HYDROGENATED AMORPHOUS SILICON FILMS AS OBSERVED USING POLARIZED FTIR-ATR SPECTROSCOPY
}

\author{
J. D. Webb, L. M. Gedvilas, R. S. Crandall, E. Iwaniczko, B. P. Nelson, A. H. Mahan, R. Reedy, \\ R. J. Matson \\ National Renewable Energy Laboratory, Golden, CO
}

\begin{abstract}
We used polarized attenuated total reflection (ATR) measurements together with Fourier transform infrared (FTIR) spectroscopy to investigate the vibrational spectra of hydrogenated amorphous silicon $\left(\mathrm{a}-\mathrm{SiH}_{\mathrm{x}}\right)$ films 0.5-1.0 microns in thickness. We deposited the films using hot-wire or plasma-enhanced chemical vapor deposition methods (HWCVD or PECVD, respectively) on crystalline silicon and cadmium telluride substrates. Our ATR technique gave a spectral range from 2100-400 $\mathrm{cm}^{-1}$, although the Si-H wagging mode absorption band at 640 $\mathrm{cm}^{-1}$ was somewhat distorted in the a-SiH$/ \mathrm{Si}$ samples by impurity and lattice absorption in the silicon ATR substrates. We report the identification of a $\mathrm{SiO}_{2}$ impurity band with maximum intensity at $1240-1230 \mathrm{~cm}^{-1}$ in p-polarization. The assignment of this band to $\mathrm{SiO}_{2}$ vibrations is supported by secondary-ion mass spectrometry (SIMS) measurements. Our polarized FTIRATR spectra of HWCVD and PECVD a-SiH $\mathrm{S}_{\mathrm{x}}$ films on $<111>\mathrm{Si}$ ATR substrates show that the impurity dipoles are oriented strongly parallel to the film growth direction. The wagging mode absorbance band is more intense in the film plane. This trend is less pronounced for the Si-H stretching vibrations. These observations are consistent with some degree of anisotropy or medium-range order in the films. The anisotropy in the Si-H bands may be related to residual stress in the films. Our scanning electron microscopy (SEM) analyses of the samples offer additional evidence of bulk structural anisotropy in the a-SiH$/ \mathrm{Si}$ films. However, the $\mathrm{SiO}_{2}$ impurity band was not observed in the polarized ATR-FTIR spectra of the a-SiH $\mathrm{S}_{\mathrm{x}} / \mathrm{CdTe}$ samples, thus indicating that the $\mathrm{Si}$ substrates influence formation of the impurity in the $\mathrm{a}-\mathrm{SiH} / \mathrm{Si}$ films.
\end{abstract}

\section{INTRODUCTION}

Infrared (IR) spectroscopy and hydrogen secondary-ion mass spectrometry (SIMS) are the two most accessible methods for determining the hydrogen content of hydrogenated amorphous silicon $\left(\mathrm{a}-\mathrm{SiH}_{\mathrm{x}}\right)$ films $[1,2]$. For IR transmission spectroscopy, the a-SiH $\mathrm{S}_{\mathrm{x}}$ films are commonly deposited on crystalline silicon substrates. However, in IR transmission, the electric field vector of the transmitted radiation is aligned predominantly with the sample plane.

Attenuated total reflection (ATR) infrared spectroscopy involves the use of an IR transparent waveguide of refractive index $\mathrm{n}_{1}$, in contact with an IR-absorbing sample of refractive index $\mathrm{n}_{2}$, where typically $\mathrm{n}_{1}>\mathrm{n}_{2}$. If infrared light is directed into the waveguide (substrate) at an incidence angle $(\theta)$ greater than its critical angle, total internal reflection takes place, except at wavelengths where the evanescent standing wave extending into the sample interacts with the IR-active dipoles and is attenuated [3]. The ATR-IR spectrum of a sample resembles its IR absorbance spectrum, except for the wavelength dependence in the ATRabsorbance band intensities induced by the wavelength-dependent penetration depth of the evanescent wave into the rarer sample medium [3]. However, in cases where $\mathrm{n}_{2}$ nearly equals or slightly exceeds $\mathrm{n}_{1}$, as with a-SiH $\mathrm{S}_{\mathrm{x}}$ films on $\mathrm{Si}$ or CdTe substrates in air, total internal reflection takes place at the sample outer surface (Fig. 1), rather than at the substrate/sample interface. In these cases there is no wavelength dependence of the ATR-absorbance band intensities [3], 
although dispersion in $\mathrm{n}_{2}$ may have some effect on the ATR-IR absorbance band shapes of $\alpha$ $\mathrm{SiH}_{\mathrm{x}}$ films on Si substrates [4]. Unlike transmission spectroscopy, ATR spectroscopy allows polarization of the incident light in the film growth direction, as well as in the film plane (Fig.1).

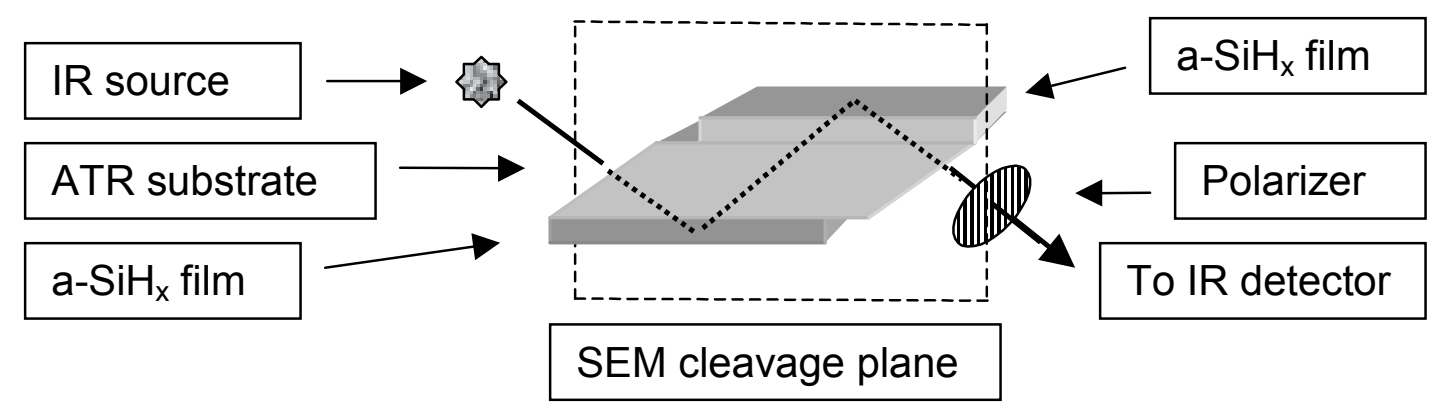

Fig. 1. Schematic drawing of the attenuated total reflection configuration for infrared spectroscopy of a-SiH $\mathrm{Silms}_{\mathrm{x}}$. The cleavage plane for SEM measurements on the $<111>\mathrm{Si}$ ATR substrates is also shown.

An early work pioneering the application of ATR spectroscopy to the analysis of a-SiH films [5] described the measurement of the first overtone absorbance of the Si-H stretching vibration near $3950 \mathrm{~cm}^{-1}$, as well as the absorbance from $3900-5400 \mathrm{~cm}^{-1}$ corresponding to highpressure molecular hydrogen in microvoids in the films. To observe these weak absorbance bands, an optical path of $6.3 \mathrm{~cm}$ through the Si ATR substrates was used. However, at such long path lengths, impurity, lattice, and free-carrier absorption in the Si substrates limited their transparency to frequencies higher than about $1500 \mathrm{~cm}^{-1}[5,6]$. In this work, we used short-pathlength $(0.7-1.4 \mathrm{~cm}) \mathrm{Si}$ and CdTe ATR substrates to extend the range of our spectroscopic measurements to frequencies as low as $400 \mathrm{~cm}^{-1}$.

\section{EXPERIMENT}

Thin films of hydrogenated amorphous silicon were deposited on both of the $<111>$ faces of crystalline silicon ATR substrates and on one face of polycrystalline cadmium telluride ATR substrates, as shown in Fig. 1. These substrates were blown clean with dry nitrogen before film deposition, but were otherwise used as received from the manufacturer (Harrick Scientific Co.), as is our typical practice in preparing a- $\mathrm{SiH}_{\mathrm{x}}$ films on $\mathrm{Si}$ substrates for IR analysis of $\mathrm{H}$ content. The gaps in film coverage of the substrate (Fig. 1) result from the clamp used to secure the substrates to the heater can in the deposition system [1]. The clamp also shielded the $45^{\circ}$ faces from the film deposition reaction. The ATR substrates were of the $45^{\circ}$ single-pass parallelepiped (SPP) type [4], and were either $10 \times 5 \times 1 \mathrm{~mm}$ or $5 \times 5 \times 1 \mathrm{~mm}$ in size. The $<111>$ orientation of $\mathrm{Si}$ and other cubic semiconductors is commonly used for ATR substrates, since it facilitates producing them in the $45^{\circ} \mathrm{SPP}$ geometry. We used hot-wire chemical vapor deposition (HWCVD) [1] and plasma-enhanced chemical vapor deposition (PECVD, or glow-discharge) [2] methods to deposit the a-SiH films. We prepared other HWCVD a-SiH $\mathrm{Silms}_{\mathrm{x}}$ on $<100>$ crystalline Si wafers. These samples were analyzed both by clamping them to an uncoated $<111>$ Si ATR substrate and by IR transmission. A Harrick Model 4XV 4x beam condenser equipped with a Perkin-Elmer wire-grid polarizer was operated with average incidence angle set to $45 \pm 15$ degrees to the film plane to collect the FTIR-ATR spectra. The wide range of actual incidence angles is caused by the $\sim \mathrm{F} 1$ beam condenser optics. The condenser optics minimized the effects of the nominally odd number of IR reflections in the $5 \times 5 \times 1 \mathrm{~mm}, 45^{\circ} \mathrm{SPP}$ ATR substrates [7]. 
The infrared spectra were collected using either a Nicolet Magna 550 FTIR spectrophotometer or a Nicolet 510 FTIR spectrophotometer with deuterated tryglycine sulfate detector. The polarized FTIR-ATR spectra (I) of the films deposited on ATR substrates were taken by averaging $10^{3}-10^{4}$ scans of the samples at $8 \mathrm{~cm}^{-1}$ resolution, and were converted to absorbance units by taking the ratio $A=-\log _{10}\left(I / I_{0}\right)$, where $I_{o}$ is the unratioed spectrum of the uncoated substrate taken at similar polarization and resolution. The polarized ATR spectra of the films deposited on Si wafer substrates were taken similarly, except that the samples were clamped to an uncoated $45^{\circ}, 10 \times 5 \times 1 \mathrm{~mm}$, SPP ATR crystal for analysis. Transmittance FTIR spectra $\left(100 \mathrm{I} / \mathrm{I}_{\mathrm{o}}\right.$, or $\left.\% \mathrm{~T}\right)$ were recorded by collecting 128 scans of the samples (I) and substrates $\left(\mathrm{I}_{\mathrm{o}}\right)$ at $4 \mathrm{~cm}^{-1}$ resolution and computing the ratio. The transmittance spectra were converted to absorbance units for comparison to the polarized ATR-absorbance spectra or were converted to absorbance coefficient spectra $\left(\alpha_{v}\right)$ for calculation of hydrogen content $[1,2]$.

After collection of their infrared spectra, some of the samples were subjected to SIMS depth profiling for $\mathrm{Si}, \mathrm{H}, \mathrm{O}, \mathrm{C}$, and/or N. The SIMS depth profiles of the samples were collected using a Cameca IMs-3f system with a $\mathrm{Cs}^{+}$primary-ion source, and detection of negative secondary ions. The diameter of the ion etch pit was $\sim 100 \mu \mathrm{m}$ at the sample surfaces. Certain of the samples were then cleaved and imaged in cross-section using scanning electron microscopy (SEM). Sample films deposited on the $<111>$ faces of Si ATR substrates were cleaved through the $<111>$ tilt plane, as indicated in Fig. 1 . The SEM images were collected with a JEOL JSM field-emission scanning electron microscope with an effective spatial resolution of $\sim 1 \mathrm{~nm}$. Table 1 gives a summary of the analyses done on each sample.

Table 1. Deposition parameters and analytical methods for a-SiH $\mathrm{S}_{\mathrm{x}}$ film samples. All films were deposited on both sides of 5x5x1 mm Si ATR substrates, unless otherwise noted.

\begin{tabular}{|c|c|c|c|c|c|}
\hline $\begin{array}{l}\text { Sample } \\
\text { Number }\end{array}$ & $\begin{array}{l}\text { Deposition Method, } \\
\text { Substrate Type }\end{array}$ & $\mathrm{T}_{\text {substrate }}(\mathrm{K})$ & $\begin{array}{l}100^{*}[\mathrm{H}] /[\mathrm{H}+\mathrm{Si}], \\
\mathrm{Si}=5 \mathrm{E} 22 \mathrm{~cm}^{-3}\end{array}$ & $\begin{array}{l}\text { Thickness } \\
(\mu \mathrm{m})\end{array}$ & Analysis Methods \\
\hline $\mathrm{H} 473$ & GD & 470.5 & $10.0^{* *}(11.5)$ & $(0.8)$ & $\begin{array}{l}\text { ATR, \%T, SIMS, } \\
\text { SEM }\end{array}$ \\
\hline $\mathrm{H} 497$ & $\begin{array}{l}\text { HW 10x5x1 CdTe, 1- } \\
\text { side }\end{array}$ & 541.5 & $9.3^{* *}$ & $1.5 \dagger$ & ATR, SEM \\
\hline $\mathrm{H} 498$ & $\begin{array}{l}\text { GD 10x5x1CdTe, 1- } \\
\text { side }\end{array}$ & 470.5 & $10.0 * *(12.3)$ & $(0.9)$ & $\begin{array}{l}\text { ATR, \%T, SIMS, } \\
\text { SEM }\end{array}$ \\
\hline T896 & HW & 541.5 & $9.8 * *(9.1)$ & $(0.5)$ & ATR, \%T, SIMS \\
\hline $\mathrm{H} 496$ & $\begin{array}{l}\text { HW, 1-side } \\
\text { stepwise deposition }\end{array}$ & 541.5 & $\begin{array}{l}9.8 * *(7.6) \\
14.0 *\end{array}$ & $(0.7)$ & ATR, \%T, SIMS \\
\hline HW64 & HW, 1-side Si wafer & 598.0 & $12.4^{*}$ & {$[0.88]$} & Contact ATR, SEM \\
\hline HW76 & HW, 1-side Si wafer & 613.0 & $8.4^{*}$ & {$[0.55]$} & Contact ATR, SEM \\
\hline HW58 & HW, 1-side Si wafer & 648.0 & $1.7 *$ & {$[1.50]$} & Contact ATR, SEM \\
\hline H350i & HW & 669.3 & $2.2 * *(2.9)$ & $(0.9)$ & ATR, \%T, SIMS \\
\hline $\mathrm{H} 472$ & $\begin{array}{l}\text { HW, 1-side } \\
\text { bilayer deposition }\end{array}$ & $\begin{array}{l}690.6 \text { (bulk), } \\
541.5(15 \mathrm{~nm})\end{array}$ & $\begin{array}{l}1.2,9.3 * *(0.3-0.6 \\
\text { bulk, } 15 \mathrm{~nm})\end{array}$ & $(0.9)$ & $\begin{array}{l}\text { ATR, \%T, SIMS, } \\
\text { SEM }\end{array}$ \\
\hline \multirow[t]{3}{*}{ H351I } & HW & 719.0 & $0 * *(0.6)$ & (4.7) & ATR, SIMS \\
\hline & & & $\begin{array}{l}\text { *FTIR } \\
\text { ( ) SIMS }\end{array}$ & $\begin{array}{l}\text { [ ] profiler } \\
\text { ( ) SIMS }\end{array}$ & \\
\hline & & & $\begin{array}{l}\text { **estimated from } \\
T_{\text {sub }}\end{array}$ & $\dagger$ SEM & \\
\hline
\end{tabular}




\section{RESULTS}

Fig. 2 shows the polarized ATR-FTIR spectrum of PECVD sample \#H473. Our ATR technique enabled detection of the $\mathrm{Si}-\mathrm{H}_{\mathrm{x}}$ fundamental stretching band from $2100-2000 \mathrm{~cm}^{-1}$ and a previously unreported $\mathrm{SiO}_{2}$ impurity band with maximum at $1240-1230 \mathrm{~cm}^{-1}$, visible only in p-polarization (parallel to the film growth direction). The shape of the wagging mode fundamental band at $640 \mathrm{~cm}^{-1}$ was distorted by the strong substitutional carbon absorbance at $607 \mathrm{~cm}^{-1}$ and by the phonon absorbance at $619 \mathrm{~cm}^{-1}$ in the Si substrates. However, a higher intensity of the $640 \mathrm{~cm}^{-1}$ band in s-polarization (parallel to the film plane) is evident, indicating some enhancement of the wagging modes in the film plane. The stretching mode band from $2100-2000 \mathrm{~cm}^{-1}$ shows little or no polarization dependence (indicating little or no orientation of the $\mathrm{Si}-\mathrm{H}$ dipoles), and is about five times more intense than the same band measured in transmission mode because of enhancement by multiple reflections. The polarized ATR-FTIR spectra of the other a-SiH $/$ /Si samples qualitatively resemble those shown in Fig. 2.

We considered assigning the impurity band to the first overtone of the fundamental $\mathrm{Si}-\mathrm{H}$ wagging vibration at $640 \mathrm{~cm}^{-1}$, but its intensity is too great, even exceeding that of the supposed parent band in the case of sample \# H472, and bears no relationship to the hydrogen content of the samples. However, the intensity of the impurity band does have a strong positive correlation with both the average oxygen (Fig. 3) and the average carbon content of the a-SiH $\mathrm{Silms}_{\mathrm{x}}$ on $\mathrm{Si}$ substrates, integrated from the film surface through the interfacial region to the substrate, as measured by SIMS. We were able to fit the polarization-dependent components of this band with the sum of two Gaussian distributions centered at 1228 and $1165 \mathrm{~cm}^{-1}$, respectively (Fig. 4). These frequencies are consistent with Si-O stretching vibrations in a crystalline $\mathrm{SiO}_{2}$ impurity phase, although carbon as $\mathrm{C}-\mathrm{O}$ could also be present in the impurity. The strong orientation of the $\mathrm{Si}-\mathrm{O}$ dipoles in the film growth direction explains why the $\mathrm{SiO}_{2}$ impurity band has not been observed previously using transmission IR spectroscopy, in

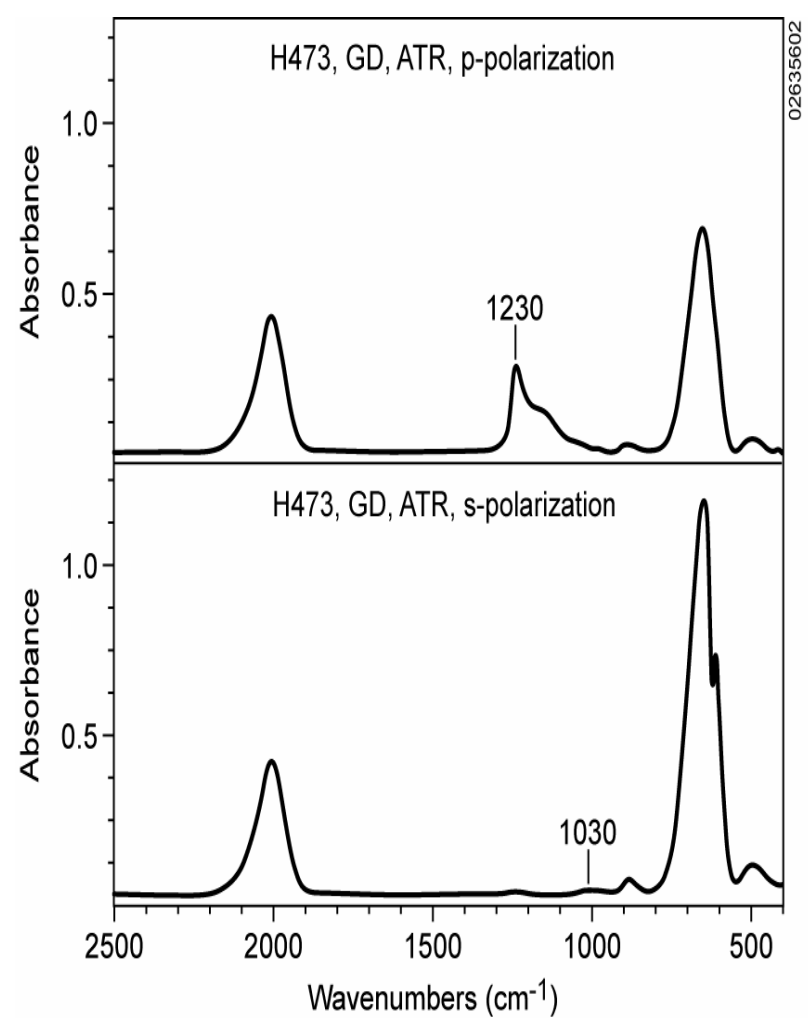

Fig. 2. Polarized FTIR-ATR spectra of a-SiH $\mathrm{x} / \mathrm{Si}$ sample \#H473. which the electric field of the incident radiation is oriented in the film plane. The impurity bands at 1228 and $1165 \mathrm{~cm}^{-1} 1$ resemble the bands reported by Chabal, et al [8] in the IR spectra of oxidized silicon wafers. There is some indication of the impurity bands in the contact FTIR-ATR spectra (not shown) of samples HW58, HW64, and HW76 (Table 1), but these spectra are noisy because of poor contact between the rigid samples and the equally rigid ATR substrates, and because of an unfavorable optical mismatch [3]. The intensity of a shoulder at $1030 \mathrm{~cm}^{-1}$ on the band structure in Fig. 4 is invariant with polarization (Fig. 2), and is consistent with an amorphous $\mathrm{SiO}_{\mathrm{x}}$ impurity phase $(1<\mathrm{x}<2)$. Fig. 5 shows that the intensity of the $\mathrm{SiO}_{2}$ impurity band is linearly dependent on the deposition time during a stepwise, single-sided HWCVD deposition of sample $\mathrm{H} 496$, for which a final film thickness of $0.9 \mu \mathrm{m}$ was measured. 


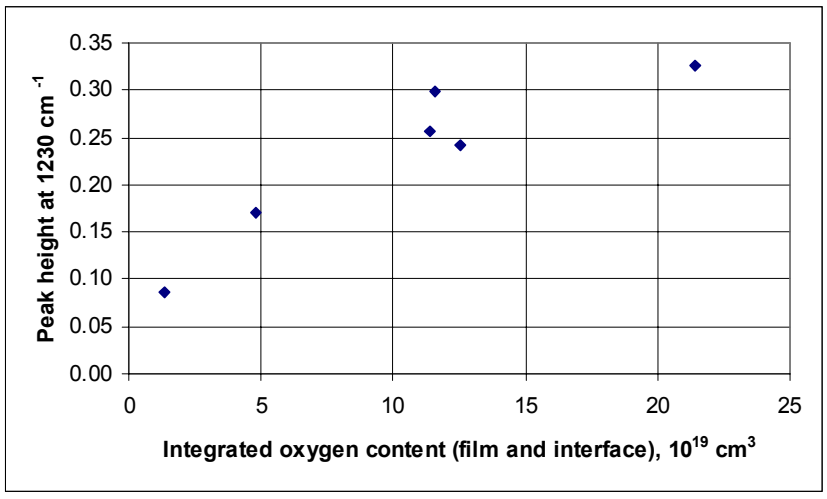

Fig. 3. Relationship between FTIR/ATR band height at $1230 \mathrm{~cm}^{-1}$ and integrated oxygen content of a-SiH $/ \mathrm{Si}$ film samples determined from SIMS depth profiles.

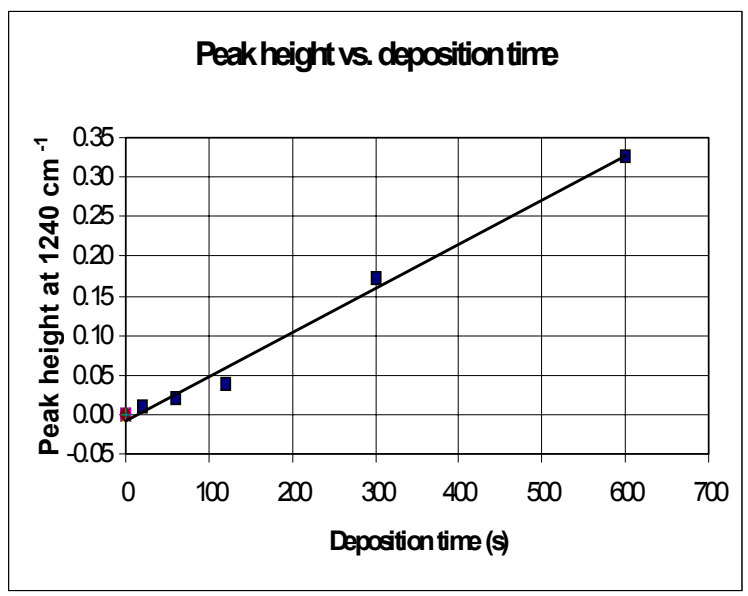

Fig. 5. Intensity of the $\mathrm{SiO}_{2}$ impurity band at $1240 \mathrm{~cm}^{-1}$ for p-polarization as a function of deposition time in stepdeposited HWCVD sample \#H496.

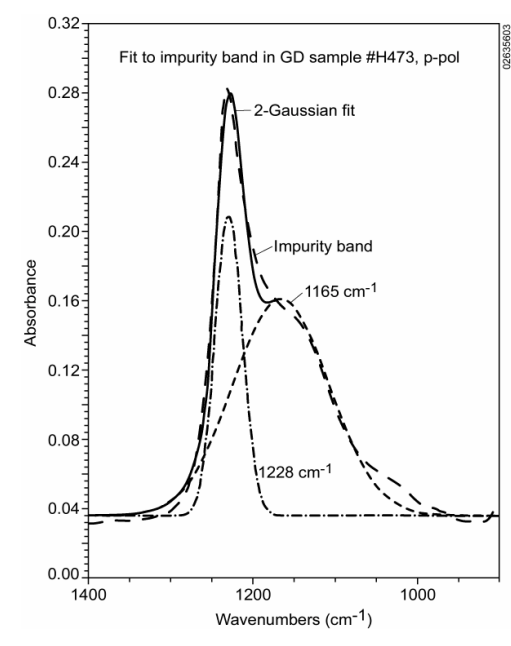

Fig. 4. Two-Gaussian fit to the $\mathrm{SiO}_{2}$ impurity band observed in the FTIR-ATR spectrum of a$\mathrm{SiH}_{\mathrm{x}} / \mathrm{Si}$ sample \#H473, with $\mathrm{v}_{1}=$ $1228 \mathrm{~cm}^{-1}, \Delta v_{1}=39 \mathrm{~cm}^{-1}, v_{2}=$ $1165 \mathrm{~cm}^{-1}$, and $\Delta v_{2}=137 \mathrm{~cm}^{-1}$.

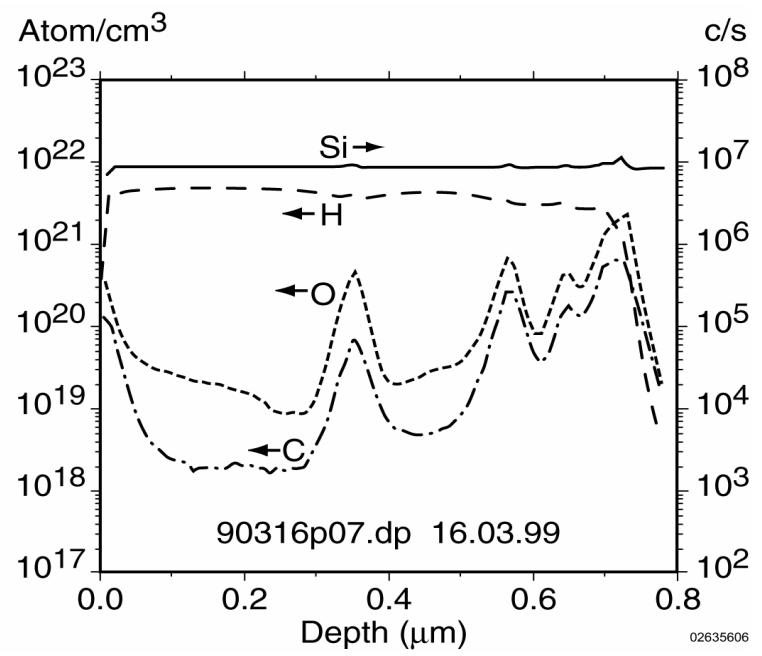

Fig. 6. SIMS Si, H, O, and $\mathrm{C}$ depth profile of layer-deposited a-SiH / $/ \mathrm{Si}$ sample \#H496.

A SIMS depth profile through sample \#H496 (Fig. 6) shows high levels of C and O at the film surface and at the film/substrate interface. These features are common to all the samples analyzed via SIMS. Also evident in Fig. 6 are accumulations of $\mathrm{C}$ and $\mathrm{O}$ at the individual deposition interfaces. These contaminants apparently accumulated when the sample was removed from the evacuated deposition chamber for FTIR-ATR spectroscopic measurements. It is likely that the $\mathrm{O}$ (and possibly $\mathrm{C}$ ) impurities introduced to the sample surface after each deposition reacted with the silane to yield the oriented $\mathrm{SiO}_{2}$ impurity phase in each subsequent deposition step during growth of this sample. Consistent with earlier results [9], the SIMS analyses show that there is little penetration of $\mathrm{H}$ into the crystalline Si substrates. 
An interesting variation in the FTIR data is the complete absence of the $\mathrm{SiO}_{2}$ impurity band in the polarized ATR spectra (not shown) of the a-SiH $\mathrm{Silms}_{\mathrm{x}}$ deposited on polycrystalline CdTe ATR substrates (H497 and H498, Table 1). Although carbon and oxygen levels in these samples were similar to those observed in some of the a-SiH${ }_{x} / \mathrm{Si}$ samples, it may also be necessary to have a surface layer rich in $\mathrm{SiO}_{\mathrm{x}}$ to serve as a precursor to the $\mathrm{SiO}_{2}$ impurity. The polarized ATR-FTIR spectra of these samples are otherwise similar to those in Figure 2, except that they show the wagging mode absorbance bandshape at $640 \mathrm{~cm}^{-1}$ without substrate absorption artifacts. The polarized ATR-FTIR spectra of samples H497 and H498 also indicate some enhancement of the wagging absorbance in the film plane. In the SEM image of HWCVD sample \#H497 (not shown), which was deposited on CdTe, the a-SiH $\mathrm{S}_{\mathrm{x}}$ film appears amorphous in areas of poor adhesion and structured in areas where it makes good contact with the substrate. The SEM images (not shown) of PECVD a-SiH $\mathrm{S}_{\mathrm{x}} / \mathrm{CdTe}$ sample \#H498 reveal no evidence of microstructure, but also show poor film adhesion, perhaps from residual stress.

The SEM micrographs of the cleaved cross-

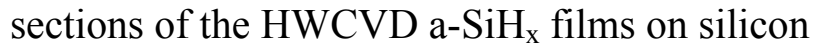
substrates show a distinct columnar microstructure and some areas of poor adhesion. The microstructure is especially evident in the SEM image of sample \#H472 (Fig. 7), which incorporated a $15-\mathrm{nm}$ a-SiH $\mathrm{Sinterfacial}_{\mathrm{x}}$ layer nominally $9.3 \%$ in $\mathrm{H}$. However, the SEM micrographs of PECVD a-SiH $/$ Si sample \#H473 (not shown) indicate that the columnar microstructure is discontinuous in this a- $\mathrm{SiH}_{\mathrm{x}}$ film.

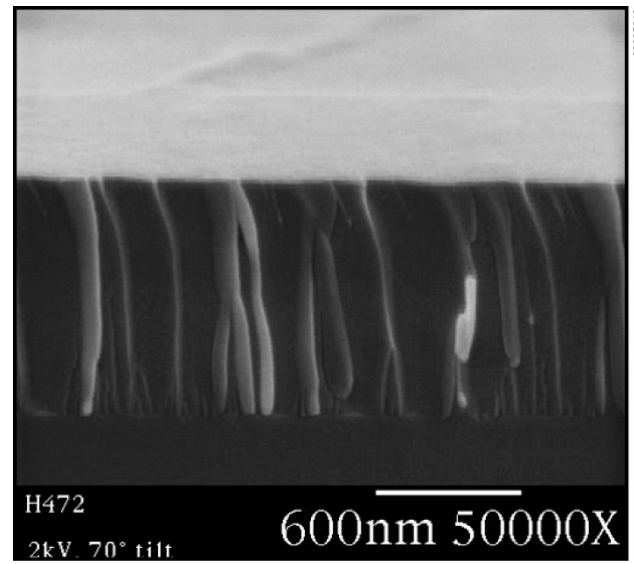

Fig. 7. Cross-sectional SEM micrograph of cleaved $\mathrm{a}-\mathrm{SiH}_{\mathrm{x}} / \mathrm{Si}$ sample $\# \mathrm{H} 472$.

\section{CONCLUSIONS}

Using polarized FTIR-ATR spectroscopy and SIMS depth profiling, we have demonstrated the existence of an impurity phase, likely to contain $\mathrm{SiO}_{2}$ and possibly $\mathrm{C}-\mathrm{O}$, and having dipoles highly oriented in the film growth direction in $\mathrm{a}-\mathrm{SiH}_{\mathrm{x}} / \mathrm{Si}$ films. The impurity phase is not observed in $\mathrm{a}-\mathrm{SiH}_{\mathrm{x}} / \mathrm{CdTe}$ films. We have also shown that the $\mathrm{Si}-\mathrm{H}$ wagging absorbance is enhanced in the film plane in $\mathrm{a}-\mathrm{SiH}_{\mathrm{x}}$ films on $<111>\mathrm{Si}$ substrates and on polycrystalline $\mathrm{CdTe}$ substrates, perhaps because of residual stress or other anisotropic properties of the films. Our SEM measurements support the FTIR-ATR measurements of structural anisotropy in the a$\mathrm{SiH}_{\mathrm{x}} / \mathrm{Si}$ films. The anisotropy is influenced more by the substrates, and their surface contaminants, than by the film deposition method. The anisotropy in the wagging absorbance at $640 \mathrm{~cm}^{-1}$ may explain some of the scatter in hydrogen content calibration measurements made using transmission-mode FTIR spectroscopy of $\mathrm{a}-\mathrm{SiH}_{\mathrm{x}} / \mathrm{Si}$ samples [1].

\section{REFERENCES}

1. B. P. Nelson, Y. Xu, A. Mason, R. Reedy, J. Webb, L. Gedvilas, and W. A. Lanford, J. Non-Cryst. Solids (1999), in press.

2. A. A. Langford, M. L. Fleet, B. P. Nelson, W. A. Lanford, and N. Maley, Phys Rev. B 45, 23, pp. 13367-13377 (1992).

3. N. J. Harrick, Internal Reflection Spectroscopy (Interscience Publishers, New York, 1967), pp. 13-66.

4. Ibid. [3], pp. 67-88.

5. Y. J. Chabal and C. K. N. Patel, Phys. Rev. Lett. 53, 2, pp. 210-213 (1984).

6. Ibid. [3], p. 144.

7. Ibid. [3], p. 130.

8. Y. J. Chabal, J. Phys. IV France 7, pp. C6-3 - C6-17 (1997).

9. B. Sopori, M. I. Symko, R. Reedy, K. M. Jones, and R. J. Matson (Proc. 26 ${ }^{\text {th }}$ IEEE PVSC, Anaheim, CA, 1997), pp. 25-30.

10. Ibid. [3], p. 31. 


\section{REPORT DOCUMENTATION PAGE}

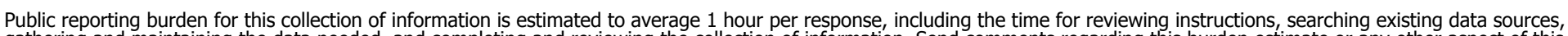

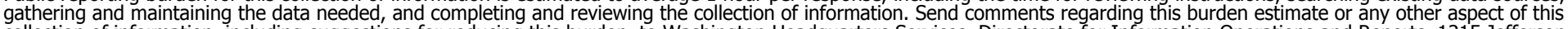

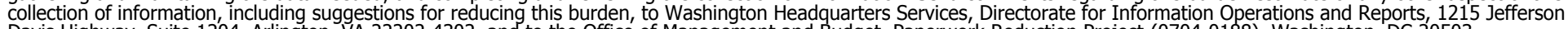

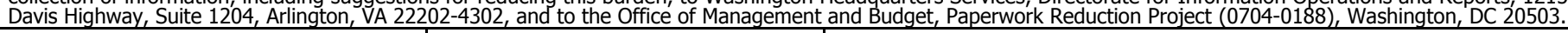

\begin{tabular}{|l|l|l|l}
\hline 1. AGENCY USE ONLY (Leave blank) & $\begin{array}{l}\text { 2. REPORT DATE } \\
\text { May } 1999\end{array}$ & $\begin{array}{l}\text { 3. REPORT TYPE AND DATES COVERED } \\
\text { Conference Paper }\end{array}$ \\
\hline 4. TITLE AND SUBTITLE
\end{tabular}

Anisotropy in Hydrogenated Amorphous Silicon Films as Observed Using Polarized FTIR-ATR Spectroscopy

6. AUTHOR(S)

J.D. Webb, L.M. Gedvilas, R.S. Crandall, E. Iwaniczko, B.P. Nelson, A.H. Mahan, R. Reedy, and R.J. Matson

7. PERFORMING ORGANIZATION NAME(S) AND ADDRESS(ES)

National Renewable Energy Laboratory

1617 Cole Blvd.

Golden, CO 80401-3393

9. SPONSORING/MONITORING AGENCY NAME(S) AND ADDRESS(ES)
5. FUNDING NUMBERS

$\mathrm{C}:$

TA: PV903101

8. PERFORMING ORGANIZATION REPORT NUMBER

10. SPONSORING/MONITORING AGENCY REPORT NUMBER

CP-520-26355

11. SUPPLEMENTARY NOTES

12a. DISTRIBUTION/AVAILABILITY STATEMENT National Technical Information Service

U.S. Department of Commerce

5285 Port Royal Road

Springfield, VA 22161

12b. DISTRIBUTION CODE

13. ABSTRACT (Maximum 200 words)

We used polarized attenuated total reflection (ATR) measurements together with Fourier transform infrared (FTIR) spectroscopy to investigate the vibrational spectra of hydrogenated amorphous silicon $\left(\mathrm{a}-\mathrm{SiH}_{\mathrm{x}}\right)$ films 0.5-1.0 microns in thickness. We deposited the films using hot-wire or plasma-enhanced chemical vapor deposition methods (HWCVD or PECVD, respectively) on crystalline silicon and cadmium telluride substrates. Our ATR technique gave a spectral range from $2100-400 \mathrm{~cm}^{-1}$, although the Si-H wagging mode absorption band at $640 \mathrm{~cm}^{-1}$ was somewhat distorted in the $\mathrm{a}-\mathrm{SiH}_{\mathrm{x}} / \mathrm{Si}$ samples by impurity and lattice absorption in the silicon ATR substrates. We report the identification of a Si-O-C impurity band with maximum intensity at $1240-1230 \mathrm{~cm}^{-1}$. The assignment of this band to a Si-O-C vibration is supported by secondary-ion mass spectrometry (SIMS) measurements. Our polarized FTIR-ATR spectra of $\mathrm{HWCVD}_{\text {and }} \mathrm{PECVD}$ a-SiH $\mathrm{x}$ films on $<111>$ Si ATR substrates show that the impurity dipoles are oriented strongly parallel to the film growth direction. The wagging mode absorbance band is more intense in the film plane. This trend is less pronounced for the Si-H stretching vibrations. These observations are consistent with some degree of anisotropy or medium-range order in the films. The anisotropy in the Si-H bands may be related to residual stress in the films. Our scanning electron microscopy (SEM) analyses of the samples offer additional evidence of bulk structural anisotropy in the a-SiH $/ \mathrm{Si}_{\mathrm{films}}$. However, the Si-O-C impurity band was not observed in the polarized ATR-FTIR spectra of the a-SiH $/ \mathrm{CdTe}_{\mathrm{x}} \mathrm{samples}$, thus indicating that the $\mathrm{Si}$ substrates influence formation of the impurity in the a-SiH $\mathrm{S}_{\mathrm{x}} / \mathrm{Si}$ films.

\section{SUBJECT TERMS}

photovoltaics ; anisotropy ; a-Si:H films ; chemical vapor deposition ; attenuated total reflection ; secondary-ion mass spectrometry ; Fourier transform infrared spectroscopy

17. SECURITY CLASSIFICATION OF REPORT Unclassified
18. SECURITY CLASSIFICATION
OF THIS PAGE Unclassified OF ABSTRACT Unclassified
19. SECURITY CLASSIFICATION
15. NUMBER OF PAGES

8

16. PRICE CODE

NSN 7540-01-280-5500

Standard Form 298 (Rev. 2-89) Prescribed by ANSI Std. Z39-18 